\title{
Lysis of Gram-Negative Bacteria by Host-Independent Ectoparasitic Bdellovibrio bacteriovorus Isolates
}

\author{
By M. SHILO* AND BARBARA BRUFF \\ Department of Bacteriology, University of California, Berkeley, California, U.S.A.
}

(Received 16 February 1965)

\begin{abstract}
SUMMARY
Methods of isolation and nutritional requirements of Bdellovibrio bacteriovorus strains capable of grow th on host-free media are described. Such strains retained their parasitic capacities for various Gram-negative bacteria after many transfers in host-free media. In parasite + host suspensions the spectrum of host specificity of various bdellovibrio strains was considerably wider than that obtained by examination for plaques on host lawns. The growth conditions therefore affect the capacity of the bdellovibrios to attach to and lyse host organisms. A proteolytic exoenzyme formed by certain bdellovibrio strains digested heat-killed, acid-treated or EDTA-treated host organisms, but did not affect intact host organisms. High phosphate concentrations inhibited exoenzyme activity. The morphological sequence of lysis induced by exoenzyme-forming parasitic bdellovibrio strains suggested that this lysis was a two-stage process : the first stage was specific attachment of bdellovibrios with damage to the cell wall of the host organisms; the second stage was non-specific digestion of cellular components by exoenzyme produced by the bdellovibrios.
\end{abstract}

\section{INTRODUCTION}

The description by Stolp \& Petzold (1962) and by Stolp \& Starr (1963) of an obligately ectoparasitic group of vibrios, Bdellovibrio bacteriovorus, highly specific in their ability to attach to and cause lysis of various Gram-negative bacteria and to form plaques on lawns of these host organisms, provided an intriguing new system for the study of mechanisms of bacterial lysis. Because of the ubiquitous occurrence of these bdellovibrios in soil and sewage, these organisms may play an important role in the ecological equilibrium of microbial populations in nature. The present work is concerned with the enrichment of cultures and the isolation of bdellovibrio strains capable of growth on artificial media in the absence of host organisms, and with their nutritional requirements. The host specificity of such bdellovibrio isolates is described and some possible mechanisms for the lysis of host organisms induced by bdellovibrios are suggested.

\section{METHODS}

Parasite strains. Three Bdellovibrio bacteriovorus strains isolated and described by Stolp \& Starr (1963) were used in this work: strain A3.12 (isolated on Pseudomonas

* Present address: Department of Microbiological Chemistry, Hebrew University-Hadassah Medical School, Jerusalem, Israel. 
fluorescens ATCC 12633); strain 109 (isolated on Escherichia coli B-2262); strain 321 (isolated on Pseudomonas phaseolicola ATcc 11355).

Host organisms. The host bacteria used in this work included: Escherichia coli B-2262, E. coli. K-12, Aerobacter aeruginosa, Proteus vulgaris, Rhodospirillum spheroides, Caulobacter sp., Pseudomonas fluorescens ATcc 12633, P. phaseolicola ATCC $11355, P$. aeruginosa, Bacillus megaterium (from the stock collection of the Department of Bacteriology, University of California at Berkeley); Pasteurella pestis Ev 76, Salmonella typhi o 901, S. typhimurium LT 2 and $S$. paratyphi $B$ (from the stock collection of the Department of Bacteriology, Hebrew University-Hadassah Medical School, Jerusalem, Israel). Other host strains used were the $\boldsymbol{E}$. coli UDP-galactose4-epimeraseless mutants: strains CM7, Gal-16 and Gal-22; and the $E$. coli strain Gal-23 defective in its ability to synthesize UDPG synthetase (UDP-glucosepyrophosphorylase). The four $E$. coli mutants were kindly given by $\mathrm{Dr}$ N. Nikaid Harvard Medical School, Boston, Mass., U.S.A.

Culture media. Nutrient broth (NB) and nutrient agar (NBA) were prepared as described by Stolp \& Petzold (1962). Dilute nutrient broth (NB/10) was prepared of 1 vol. $\mathrm{NB}+9$ vol. solution in distilled water containing: $\mathrm{Ca}\left(\mathrm{NO}_{3}\right)_{2}, 200 \mathrm{mg}$./l.; $\mathrm{FeSO}_{4}, 10 \mathrm{mg} . / \mathrm{l} . ; \mathrm{MnSO}_{4}, 10 \mathrm{mg} \cdot / \mathrm{l}$.

Medium C was composed of: Hutner's vitamin-less base (Cohen-Bazire, Sistrom \& Stanier, 1957), 5 ml./l.; $\mathrm{Na}_{2} \mathrm{HPO}_{4}, 1.9$ g./l.; $\mathrm{KH}_{2} \mathrm{PO}_{4}, 0.9$ g./l.; Bacto-peptone, $10 \mathrm{~g} . /$ 1.; Difco yeast-extract, $1 \mathrm{~g}$./l.; thiamine $\mathrm{HCl}, 2 \mathrm{mg}$./l. (filter sterilized and added to autoclaved components of medium). For the preparation of solid medium $\mathbf{C , ~} 0.85 \%$ (w/v) Ion-Agar (Oxoid) was added. Soft agar was prepared by adding $0.8 \%(w / v)$ Bacto agar to the liquid medium NB/10.

Plaque formation by bdellovibrios on lazons of their hosts. The host inoculum used was a suspension $\left(2 \times 10^{7}\right.$ organisms) of bacteria in the late exponential phase of growth. Samples of $0.2 \mathrm{ml}$. of the host suspension were placed in tubes containing $2 \mathrm{ml}$. liquefied soft agar medium together with $0.1 \mathrm{ml}$. of a selected suspension of the bdellovibrio and then spread evenly on the surface of NB/10 agar plates. The host bacteria formed a confluent lawn on the surface of the plate within $24 \mathrm{hr}$ of incubation at $30^{\circ}$; plaques generally appeared $12-24 \mathrm{hr}$ later.

Lysis of suspension of host bacteria by bdellovibrios. The host bacteria were grown, in NB medium for $20 \mathrm{hr}$ at $30^{\circ}$ on a shaker. Washed host bacteria and bdellovibrios were suspended in NB/10 medium at the desired host: parasite ratio and the mixtures $(10 \mathrm{ml}$.) in $50 \mathrm{ml}$. Erlenmeyer flasks fitted with Klett tube side arms incubated in a shaker bath at $30^{\circ}$. The decrease in extinction (Klett-Summerson colorimeter filter 66) of the suspension mixture as a function of time served as the measure of lysis.

Enumeration of particles by use of an electronic particle counter. Particles in the size range of the bdellovibrios were enumerated by the use of an electronic particle counter (Coulter counter, Model A, Coulter Electronics, Hialeah, Fla., U.S.A.) with an orifice of $30 \mu$, and having the following instrument settings: aperture current setting, 5; gain switch, 6; gain trim, 9. To obtain a dilution medium of low particle background, NB/10 medium was repeatedly filtered through packs of Whatman No. 1 filter paper and finally through a Millipore filter (0.22 $\mu$ pore size). 


\section{RESULTS}

\section{Isolation and properties of host-independent Bdellovibrio bacteriovorus mutants}

By using the parasitic Bdellovibrio bacteriovorus strain A3.12 isolated on Pseudomonas fluorescens as starting material, several mutants were obtained which were capable of growth on artificial media in the absence of host bacteria, but which, nevertheless, retained their capacity to attach to and to lyse living host organisms. Enriched suspensions of such mutants were obtained by methods which included physical separation of the small bdellovibrios from their larger hosts by filtration through a Millipore filter $\left(0.45 \mu\right.$ pore size). Large initial populations $\left(\sim 10^{9}\right.$ organisms $/ \mathrm{ml}$.) of Bdellovibrio A3.12 (wild-type) were required since heavy losses of organisms occurred during the filtration process. The host-free parasite-containing filtrates were transferred into media $\mathrm{NB}$ or $\mathrm{C}$ or into $\mathrm{NB} / 10$ (containing heat-killed $\left[120^{\circ}\right.$, $15 \mathrm{~min}$.] $P$. fluorescens, $\sim 10^{8}$ organisms $/ \mathrm{ml}$.) and incubated at $30^{\circ}$ with vigorous shaking. The several B. bacteriovorus A 3.12 isolates which grew under these conditions were maintained for many months in transfers on host-free media (NB or C). The predacity of such isolates was retained and was not lost upon lyophilization.

The generation time of these host-independent mutants (on media NB or C, shaker incubated at $30^{\circ}$ ) was $170-180 \mathrm{~min}$. In the exponential phase of growth, the bdellovibrios were actively motile and of uniform size. As the culture entered the stationary phase, the number of motile bdellovibrios decreased and spirals and long rods appeared. Several days after the cessation of growth, degenerate forms became evident, characterized by cytoplasmic spheres at the end of the spiral-like organism (Pl. 1, fig. 1).

The vitamin requirement of a host-independent Bdellovibrio bacteriovorus A 3.12 mutant is shown in Table 1 . The yeast extract in medium $\mathbf{C}$ could be partially replaced by thiamine; however, the yeast extract seemed to contain at least one other factor essential for growth of B. bacteriovorus A3.12.

On solid media $\mathrm{C}$ and NB agar, excessively large inocula of the bdellovibrios were required for growth initiation; minimal inoculum for colony formation of hostindependent mutants, under these conditions, was found to be on the order of $10^{4}$ organisms/plate. The addition of $1 \%(\mathrm{v} / \mathrm{v})$ autoclaved culture supernatant fluid of the same bdellovibrio strain grown in NB medium provided a growth-initiating factor, making possible regular production of isolated colonies from suitably diluted bdellovibrio suspensions. The growth-initiating factor was present in supernatant fluids of bdellovibrio cultures after $24 \mathrm{hr}$ of incubation in NB medium; in 8-day cultures the concentration of this factor seemed to be markedly higher. In the presence of bdellovibrio culture supernatant fluids, the colonial growth of bdellovibrio mutants was rapid at $30^{\circ}$ (within $48 \mathrm{hr}$ ) and the ratio of total counts estimated in a Petroff-Hauser chamber (American Hosp. Supply Corp., Phila., Pa., U.S.A.) to colony numbers approached unity.

The host-independent Bdellovibrio bacteriovorus A 3.12 mutants, when mixed with their pseudomonad host immediately attached to the host bacteria (Pl. 1, fig. 2). The typical morphological changes in the host, leading to lysis, consisted in the formation of V-like and ring structures, when induced by the wild-type $B$. bacteriovorus A 3.12; these were also observed with the host-independent mutants (Pl. 1, figs. 3-5). Upon lysis of the pseudomonad host, ghosts of similar shape remained and no 
formation of an intermediate spheroplast stage was observed. The host-independent isolates attached to susceptible host bacteria only during the exponential and early stationary phases of the growth of the bdellovibrios.

Plaques were formed on lawns of Pseudomonas fluorescens, and among the various isolates, a number of types forming plaques of different size and opacity were observed (Pl. 1, figs. 6-8). Size of such plaques ranged from 1 to $10 \mathrm{~mm}$. after 4-5 days' incubation at $30^{\circ}$.

Table 1. Vitamin requirements of Bdellovibrio bacteriovorus

\title{
A3.12 host-independent mutant
}

\begin{abstract}
Basal medium consisted of 0.02 m-phosphate buffer (pH 7.0), 5 ml./l. Hutner's base and peptone ( $10 \mathrm{~g} . / 1$.$) as carbon source. The amount of each vitamin (\mu \mathrm{g} . / 1$.$) : riboflavin 0.2$; thiamin $\mathrm{HCl}, 2.0$; folic acid, 0.004 ; nicotinic acid, 0.8 ; calcium pantothenate, 0.8 ; cobalamin $\left(\mathrm{B}_{12}\right), 2 \cdot 0$; biotin, $0.004 ; p$-aminobenzoic acid, 0.2 ; pyridoxal phosphate, 0.8 ; pyridoxamine $\mathrm{HCl}, 0 \cdot 8$.
\end{abstract}

\begin{tabular}{|c|c|c|c|c|c|c|c|c|c|c|c|c|}
\hline $\begin{array}{l}\text { 疍 } \\
\text { 兽 } \\
\text { 号 }\end{array}$ & 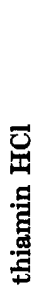 & 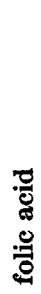 & 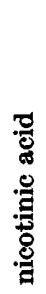 & 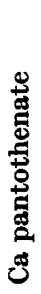 & 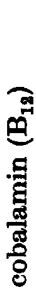 & 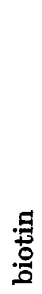 & 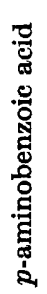 & 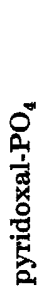 & 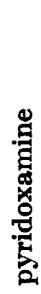 & 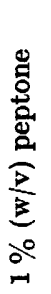 & 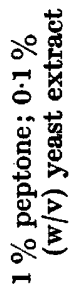 & 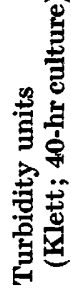 \\
\hline+ & + & + & + & + & - & + & + & + & + & + & - & 230 \\
\hline+ & + & + & + & + & + & + & - & + & + & + & - & 230 \\
\hline+ & + & + & + & - & - & + & + & + & + & + & - & 230 \\
\hline+ & + & - & + & + & + & + & + & + & + & + & - & 240 \\
\hline+ & + & - & + & + & + & + & - & + & + & + & - & 230 \\
\hline+ & + & + & + & + & - & - & - & - & - & + & - & 200 \\
\hline+ & + & + & + & - & - & - & - & - & - & + & - & 230 \\
\hline+ & + & - & + & + & + & - & - & - & - & + & - & 230 \\
\hline+ & - & + & + & + & - & + & + & + & + & + & - & 50 \\
\hline+ & - & + & + & + & + & + & - & + & + & + & - & 40 \\
\hline- & - & - & - & - & - & + & + & + & + & + & - & 50 \\
\hline- & - & - & - & - & + & + & - & + & + & + & - & 50 \\
\hline+ & - & + & + & + & - & - & - & - & - & + & - & 50 \\
\hline- & - & - & - & - & - & - & - & - & - & + & - & 50 \\
\hline+ & + & + & + & + & + & + & + & + & + & + & - & 230 \\
\hline- & + & - & - & - & - & - & - & - & - & + & - & 260 \\
\hline- & - & - & - & - & - & - & - & - & - & - & + & 320 \\
\hline- & + & - & - & - & - & - & - & - & - & - & + & 360 \\
\hline
\end{tabular}

To determine whether host-independent bdellovibrio isolates retained their predacity after cultivation in the absence of host bacteria, the plaque-forming efficiency of several of the Bdellovibrio bacteriovorus $\mathrm{A} 3.12$ isolates on host lawns of Pseudomonas fuoroscens was tested. At different growth phases, the bdellovibrio cultures were tested for plaque-forming capacity on NB/10 and compared to the colony-forming ability on solid medium $C$. In addition, the most probable number of viable organisms in the bdellovibrio suspension was estimated by the dilution tube technique (McCrady, 1918) in liquid medium C. For determination of the total number of parasites in suspension, particles in the size range of the parasite were counted in an electronic particle counter, and these results were corroborated in a number of experiments by direct counts in a Petroff-Hauser chamber. 
Figure 1 summarizes the results of an experiment comparing numbers of plaques formed by a host-independent isolate to numbers of organisms counted by the other methods. In the early growth stage (first $5 \mathrm{hr}$ ) every particle in the suspension was viable and capable of forming a plaque. In these cultures, therefore, predacity was retained by practically every organism. After $10 \mathrm{hr}$ of incubation in this medium, nearly every particle in the bdellovibrio size-range was viable, but only one out of every five organisms was capable of plaque formation.

Similarly, the number of viable cells from the lysed, $8 \mathrm{hr}$ culture of a host-independent Bdellovibriobacteriovorus a 3.12 mutant grown continuously in two-membered cultures with its host $P$ seudomonas fluorescens was determined by plaque count and by

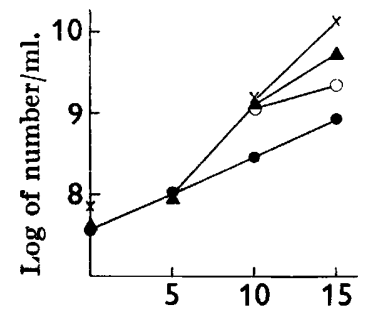

Age of culture (hr)

Fig. 1

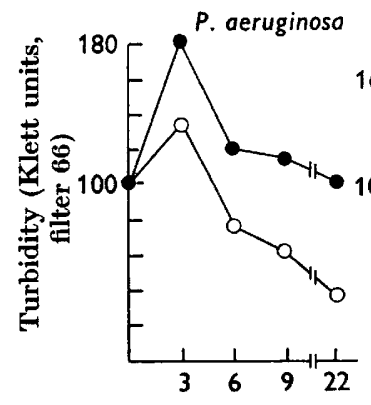

Fig. 1. Total and viable counts of host-independent Bdellovibrio bacteriovorus A 3.12 isolate measured by different methods during exponential growth stage on nutrient broth. - plaque-forming units; $\Delta$ viable count, colonies; $O$ viable count, dilution tube technique; $\times$ particle number, Coulter electronic counter.

Fig. 2. Lysis of suspension of different host species by host independent $B$. bacteriovorus A3.12 isolate. Conditions of lysis as described under Methods; the ratio of parasites to host organisms was 10:1 in all tests. Solid points are host controls; open points are host + parasite suspension. Key to host species: $\bigcirc$ Pseudomonas aeruginosa; $\Delta \Delta$ Escherichia coli $\mathrm{K}$ 12; $\nabla \nabla$ Salmonella paratyphi B; $\square \square S$. typhi o901; $\diamond$ Pasteurella pestis Ev76.

Table 2. Ability of host-independent Bdellovibrio bacteriovirus a 3.12 isolates, grown continuously in two-membered cultures, to develop in the absence of host organism

$\begin{array}{ccr}\text { Expt. } & \overbrace{\text { plaque count }}^{\text {Viable bdellovibrios } / \text { ml. found by: }} \\ 1 & 1 \times 10^{9} & \begin{array}{r}\text { dilution* } \\ 2\end{array} \\ 3 \times 10^{8} & 3 \times 10^{8} \\ 3.5 \times 10^{8}\end{array}$

* Dilution medium; medium C containing 2-4 $\mu \mathrm{g}$. thiamine $\mathrm{HCl} / \mathrm{ml}$.

dilution-tube technique. The results of two experiments (Table 2) show that practically every plaque forming unit was also able to grow in absence of host bacteria.

After prolonged subcultivation in host-free media, several host-independent isolates showed a progressive decrease in predacity as measured by the ratio of plaqueforming units to viable organisms in cultures. Such organisms, on microscopic examination, showed no loss of motility. 
Specificity of attachment to host bacteria and then lysis by Bdellovibrio bactieriovorus A 3.12 isolates and B. bacteriovorus 109

All the bdellovibrio strains isolated by Stolp \& Petzold (1962) and Stolp \& Starr (1963) were separated into different groups according to their plaque-forming ability for specific hosts. In our work, the ability of the parasite to attach to and lyse host organisms in suspension showed that under such conditions the spectrum of host specificity was often markedly broader than that observed when plaque formation was the sole criterion. Thus, (wild-type) Bdellovibrio bacteriovorus A3.12 and its host-independent mutants were capable of lysing suspensions of many living Gramnegative organisms, including Escherichia coli $\mathrm{B}, E$. coli $\mathrm{K}-12$, Pseudomonas aeruginosa, Salmonella typhimurium LT2, S. paratyphi B, S. typhi o 901 and Pasteurella pestis Ev76, all of which did not show plaque formation. Certain other Gram-negative organisms, such as Caulobacter sp., Rhodopseudomonas spheroides, Rhodospirillum rubrum and the Gram-positive bacterium Bacillus megaterium did not show attachment and lysis in suspension.

The kinetics of lysis in suspension of several host species with a host-independent Bdellovibrio bacteriovorus A3.12 isolate are shown in Fig. 2. The residual turbidity seen in these mixtures was due to ghosts of host bacteria and to the parasite organisms, which were visible on microscopic examination.

Figure 3 shows the effect of the degree of multiplicity (parasite:host ratio) on the rate of lysis of Escherichia coli $\mathbf{B}$ in suspension with a Bdellovibrio bacteriovorus A3.12 mutant. As can be seen from Fig. 3, the rate of lysis was dependent on the degree of multiplicity and even with a low ratio of two parasites one bacterium lysis of the host occurred.

To test whether the lysis of suspensions of host bacteria not suitable for plaque formation involved a selective enrichment of bdellovibrios having different and broader host specificities, the following experiment was done. The plaque-forming efficiency of a host-independent Bdellovibrio bacteriovorus A3.12 mutant on each host bacteria was tested before and after a series of three sequential transfers of the bdellovibrio on each of the following host suspensions : Escherichia coli $\mathrm{B}$, E. coli $\mathrm{K}-12$, Aerobacter aeruginosa and Pseudomonas fluorescens (the specific 'plaque-forming' host). Even after these repeated transfers and total lysis of the different hosts in suspension, no enriched suspension of any bdellovibrio mutant with new host plaqueforming specificity was found. The parasites of every one of the four transfer lines showed the same high plaque-forming capacity on $\boldsymbol{P}$. fluoroscens $(0 \cdot 1-1 \cdot 0$ plaques/ parasite) and very low plaque formation $\left(\geqslant 10^{-6}\right.$ plaques/parasite) on any of the other host species tested. Similarly, tests of isolates from some of the rare plaques formed by the bdellovibrio strain on $E$. colior $P$. aeruginosa showed that such isolates did not develop plaque-forming specificities differing from that of the initial strain.

Bdellovibrio bacteriovorus strain 109 lysed suspensions of several Escherichia coli mutants (including the UDP-galactose-4-epimeraseless strains cM7, Gal-16, Gal-22) which are deficient in ability to synthesize normal cell wall-lipopolysaccharides when grown on a galactose-free, glucose-containing mineral medium (Yarmolinsky, Wiesmeyer, Kalckar \& Jordan 1959). Similarly, lysis was obtained in suspensions of the E. coli Gal-23 mutant (low in UDPG synthetase; Fukasawa, Jokura \& Kurahashi, 1962; Sundarajan, Rapin \& Kalckar, 1962) with the B. bacteriovorus 109 strain. 


\section{Protease formation by various bdellovibrio strains}

Bdellovibrio bacteriovorus A 3.12 (grown in the presence of its specific host Pseudomonas fluorescens) or its host-independent mutants all grown in NB or NB/10 media released a potent protease into the medium. This exoenzyme lysed many different heat-killed bacteria (Fig. 4) dissolving most of the internal components of the bacteria and leaving empty hulls of cell walls. This exoenzyme also degraded typical protease substrates such as the coloured collagen preparation Azocoll (Calbiochem AG, Lucerne, Switzerland; Fig. 4). The spectrum of lytic activity against the heated bacteria extended beyond that observed with these parasites against living hosts in suspensions, and even included Gram-positive organisms such as Bacillus megaterium.

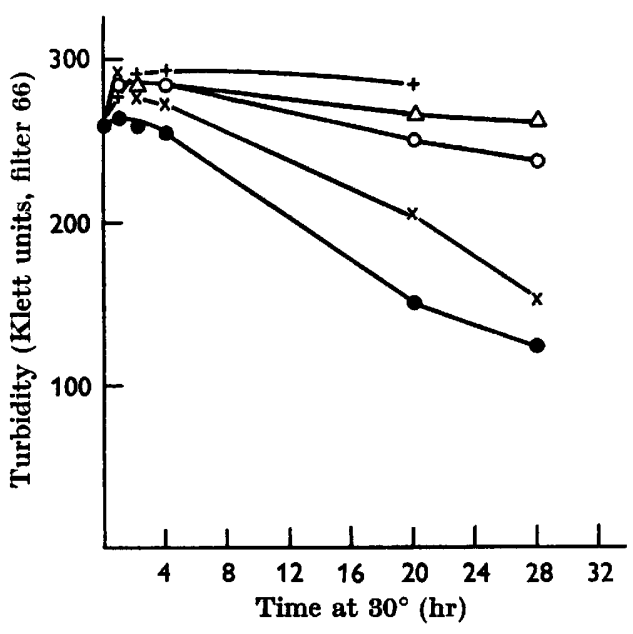

Fig. 3

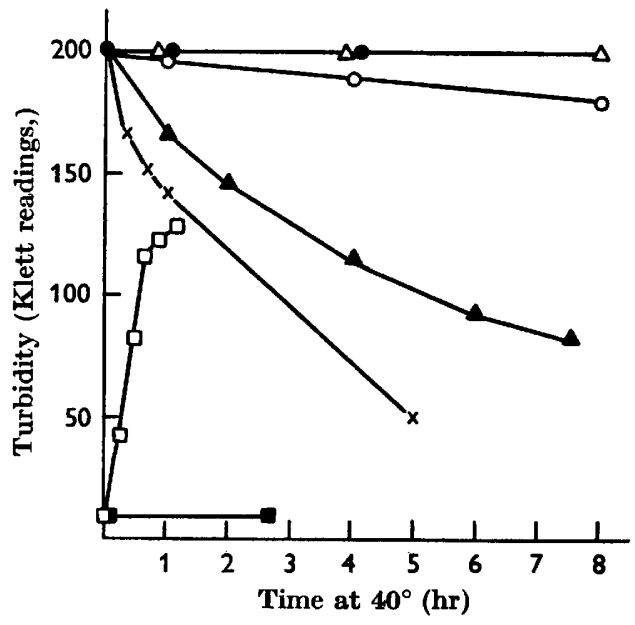

Fig. 4

Fig. 8. Effect of parasite-host ratio on rate of lysis of living Escherichia coli B in suspension with host independent Bdellovibrio bacteriovorus $\mathbf{A 3 . 1 2}$ isolate. Conditions of incubation as described under Methods for lysis of host suspensions. The parasite and host suspensions were mixed to give the desired parasite: host ratios. Ratio of parasite organisms to host organisms: $2: 1[\triangle] ; 5: 1[O] ; 12: 1[\times] ; 24: 1[0]$; host control $[+]$.

Fig. 4. Digestion of different heat-killed bacteria and decomposition of Azocoll by culture supernatants of different bdellovibrio strains. Cell-free supernatants of $48 \mathrm{hr}$ cultures of host independent strain A 3.12 or of two membered cultures of strain 109 or 321 on their specific hosts were obtained by centrifugation $(20$ min. at 15,000 r.p.m., Servall SS-1 at $\left.3^{\circ}\right)$. Heat killed $\left(120^{\circ}, 10\right.$ min.) Pseudomonas fiuorescens or $B$. megaterium were suspended, respectively, in parasite culture supernatant and incubated at $40^{\circ}$. Proteolytic activity was measured by decrease in extinction (Klett-Summersen colorimeter, filter 66). $50 \mathrm{mg}$. Azocoll were suspended in $10 \mathrm{~m}$. strain A3.12 culture supernatant. Mixture was incubated at $40^{\circ}$; at specified times, $2 \mathrm{ml}$. aliquots were removed, filtered and turbidity of 1 part of filtrate diluted in 4 parts distilled water was read (Klett-Summersen colorimeter, filter 54). Pseudomonas fluorescens and Bacillus megaterium controls. $\triangle$ Bdellovibrio bacteriovorus 321 culture supernatant $+P$. fluorescens. $O$ B. bacteriovorus 109 culture supernatant $+P$. fluorescens. $\triangle B$. bacteriovorus A 3.12 culture supernatant + B. megaterium. $\times B$. bacteriovorus A3.12 culture supernatant $+P$. fluorescens. $\square B$. bacteriovorus A 3.12 culture supernatant + Azocoll. $\square$ Azocoll control.

Figure 5 shows the formation of protease exoenzyme in a growing bdellovibrio culture as a function of time. Maximal exoenzyme activity in culture supernatant fluids was found at the time when the rapid decline in bdellovibrio numbers began 
(24-48 hr). It can also be seen from Fig. 5 that the enzyme activity was rapidly lost.

The exoenzyme activity of the Bdellovibrio bacteriovorus A 3.12 culture supernatant fluids in dissolving heat-killed bacteria was markedly suppressed by phosphate at $10^{-1}$ to $10^{-2} \mathrm{M}$ (Fig. 6). Similar phosphate inhibition of enzyme activity was observed in the decomposition of Azocoll.

Tests for exoenzyme formation by other bdellovibivrio strains showed that strains 321 and 109 did not form any protease, or only trace amounts (see Fig. 4), when grown on their specific hosts in NB medium. These two strains also differ from $\mathrm{A}$ 3.12 in the morphological sequence which leads tolysis of their host organisms. With strains 321 and 109 , lysis involved the formation of cytoplasmic extrusions (strain 321, Pl. 2, figs. 1-4) or spheroplast formation (strain 109, Pl.2, fig. 5).

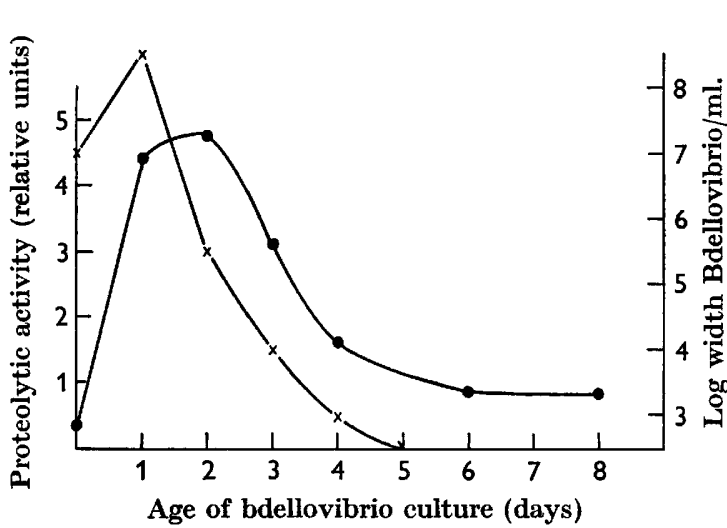

Fig. 5

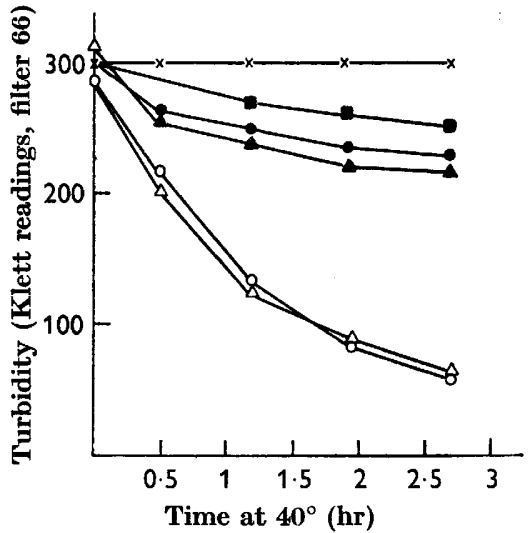

Fig. 6

Fig. 5. Formation of proteolytic exoenzyme in host-independent Bdellovibrio bacteriovorus A 3.12 isolate cultures (in NB medium).$\times$ Number of viable bdellovibrios measured by colony formation on solid medium $\mathrm{C}$. Proteolytic activity of parasite culture supernatant fluid as measured by decrease in turbidity of standard suspension with heat-killed Pseudomonas fluorescens $\left(120^{\circ}, 10 \mathrm{~min}\right.$.) incubated for $50 \mathrm{~min}$. at $37^{\circ}$.

Fig. 6. Inhibitory effect of phosphate on exoenzyme activity of host-independent A3.12 culture supernatant fluid. Heat-killed Pseudomonas fluorescens $\left(120^{\circ}, 10 \mathrm{~min}\right.$.) was suspended in parasite culturesupernatant fluid (from 48-hr host-independent Bdellovibrio bacterivorus a 3.12 culture in NB medium) prepared as described for Fig. 4. Different buffers were added to give final $\mathrm{pH}$ values and molarities as indicated below. Control, nutrient broth only [ $\times$ ]; Sørensen buffer 0.1 M, pH 6 [G]; Sørensen buffer 0.1 м, pH 7 [0]; Sørensen buffer $0.1 \mathrm{M}, \mathrm{pH} 8$ [ $\triangle$ ]; Tris buffer $0.2 \mathrm{M}, \mathrm{pH} \mathrm{8.4.}[\triangle]$; pH 8, no buffer added [O]. Conditions of incubation and measurement of lysis were as for Fig. 4.

Table 3. Analyses of the predacity of host-independent Bdellovibrio bacteriovorus A 3.12 mutants during successive transfers in pure culture

Viable count by:

$\begin{array}{ccccc}\text { Transfer } & \text { Dilution } & \text { Colony count } & \text { Plaque count } & \begin{array}{r}\text { Plaque } \\ \text { dilution }\end{array} \\ \text { 5th } & 1.2 \times 10^{9} & \mathbf{3 . 5} \times 10^{8} & 1.2 \times 10^{9} & \mathbf{1 . 0 0} \\ \text { 10th } & 1.6 \times 10^{9} & 1.4 \times 10^{9} & 0.4 \times 10^{9} & 0.25 \\ \text { 26th } & \mathbf{8 . 5} \times 10^{9} & 8 \times 10^{9} & 1 \times 10^{8} & 0.01\end{array}$




\section{Sensitization of bacteria to bdellovibrio exoenzyme}

Cell-free exoenzyme preparations of Bdellovibrio bacteriovorus A 3.12 did not affect intact living organisms of their hosts (Pseudomonas fuorescens, Escherichia coli $\mathbf{\text { B, }}$ E. coli $\mathrm{K}-12)$ in suspension. However, when such host bacteria were heated $\left(70^{\circ}, 10 \mathrm{~min}\right.$.) or treated with various agents such as $5 \%$ butanol, acid or EDTA, which damage cell walls, in a manner similar to those described by Noller \& Hartsell $(1961 a, b)$, the bacteria were rendered sensitive to lysis by the exoenzyme. When such cell-free culture supernatant fluids were added to pseudomonas host bacteria immediately after these hosts had attached a multiplicity of washed host-independent $B$. bacteriovorus A3.12 mutant, an enhancement in the rate of lysis was observed over and above that observed when similar host + mutant mixtures were suspended in the growth medium alone.

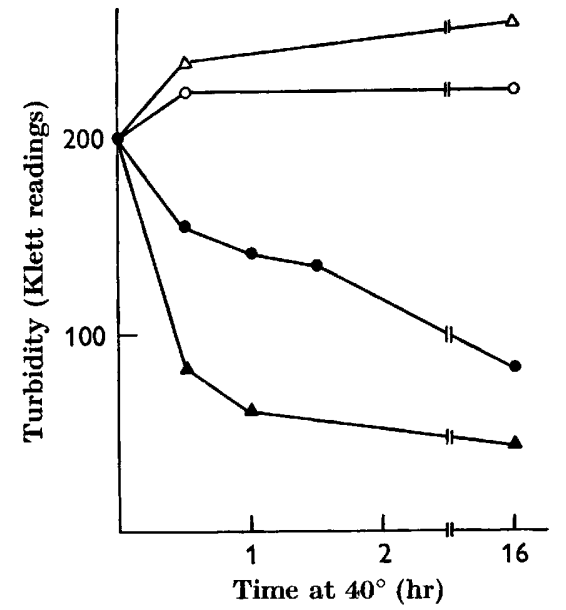

Fig. 7

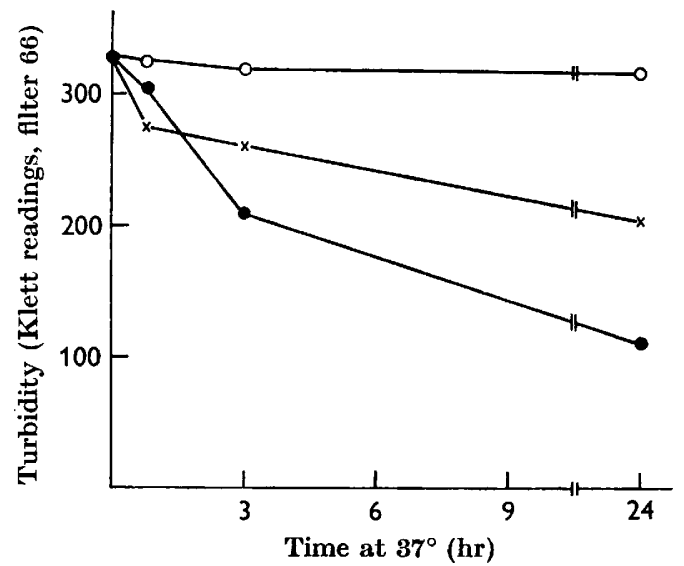

Fig. 8

Fig. 7. Effect of acid treatment of host bacteria on their sensitivity to lysis by bdellovibrio exoenzyme. Washed host bacteria were incubated for $50 \mathrm{~min}$. at $40^{\circ}$ at $\mathrm{pH} 2$ ( $\mathrm{pH}$ adjustment with dilute $\mathrm{HCl}$ ). After neutralization, lysis was followed in suspension with host-independent Bdellovibrio bacteriovorus A 3.12 culture supernatant fluid (prepared as described under Fig. 4), incubated at $37^{\circ}$. Escherichia coli $\mathrm{B}+$ B. bacteriovorus $\mathbf{A 3 . 1 2}$ culture supernatant fluid. $O E$. coli B control. $\triangle$ Pseudomonas fluorescens $+B$. bacteriovorus A 3.12 culture supernatant fluid. $\triangle P$. fluorescens control.

Fig. 8. Effect of EDTA on sensitivity of Pseudomonas fluorescens to lysis by parasite exoenzyme. Living Pseudomonas fluorescens (from $24 \mathrm{hr}$ cultures) were incubated with EDTA (di-sodium salt; Matheson, Coleman and Bell, Norwood, Ohio; final concentration, $133 \mu \mathrm{g}$. EDTA $/ \mathrm{ml}$.) in the presence and absence of the $B$. bacteriovorus $\mathrm{A} 3.12$ culture supernatant fluid (prepared as for experiment of Fig. 4). All tests were made at pH 8.5, $37^{\circ}$. O B. bacteriovorus A 3.12 culture supernatant fluid only; EDTA $+B$. bacteriovorus A 3.12 culture supernatant fluid; $\times$ EDTA in nutrient broth.

Figure 7 shows the effect of acid treatment of bacteria on their sensitivity to lysis by exoenzyme; Fig. 8 summarizes the effect of EDTA on the lytic activity of the exoenzyme. 


\section{DISCUSSION}

Bdellovibrio bacteriovorus at present occupies a unique position in the microbial world: it is the first example of a group of bacteria specifically able to attach to and to lyse certain other bacteria. In addition, the widespread occurrence of bdellovibrios as shown in soil and sewage samples in Germany and California (Stolp \& Petzold, 1962; Stolp \& Starr, 1963) and recently in soil samples in Israel (Miss M. Varon, private communication) suggests their possible ecological importance.

The isolation of predacious bdellovibrios in axenic cultures was a step towards a better understanding of the inter-relationship between parasite and host. With such cultures, an approach has been made in the present work towards the elucidation of the nutritional requirements of the parasite and the mechanisms of bacterial lysis induced by it.

Several earlier attempts by Stolp \& Petzold (1962) and Stolp \& Starr (1963) to isolate host-independent strains appeared to involve the loss of predacity and motility. In our experiments with Bdellovibrio bacteriovorus A 3.12 isolates, however, even after repeated subcultivation, most of the parasite organisms retained their predacity. The media used in this work fully supplied the nutritional requirements of these mutants, although massive inocula ( $10^{4}$ organisms/plate) were required to initiate colony formation on the NB agar or $\mathrm{C}$ agar media. The addition to the solid media of cell-free parasite culture fluid showed that the fluid had growth-initiating ability and abolished the growth-controlling effect of the inoculum. The growthinitiating factor was relatively heat stable; its activity was retained after heating to $120^{\circ}$ for $15 \mathrm{~min}$. A similar effect was observed by Mager (1964) for different strains of Pasteurella tularensis, where a growth-initiating factor present in culture supernatant fluid or cell extracts induced in recipient pasteurellas a capacity to synthesize new growth-initiating factor, thus insuring a continuous self-supply by the proliferating cultures.

The spectrum of host specificity of bdellovibrio strains was markedly dependent on the conditions prevailing during host/parasite interaction. The lytic spectrum of various host bacteria in suspension was broader than when plaque-formation was used as criterion for host specificity, and therefore appears to be a more useful way to assess the host specificity of the parasites. The much more restricted host range for plaque formation, as opposed to the ability of the parasite to attach to and to lyse different bacterial hosts in suspension, may be explained by the fact that plaque formation involves, besides attachment and lysis, the capacity of the parasite to multiply and spread in the presence of the multiplying host bacterium. Inhibition of growth by host metabolites could thus prevent plaque formation by parasites on solid media.

Lysis of host bacteria by certain predacious bdellovibrio strains, such as A3.12, seems to involve two stages, of which the first is the attachment of the bdellovibrio to its specific bacterial host; during this stage some damage of the outer layer of the host cell wall probably occurs. This damage may unmask or dissociate components of the inner layers of the cell wall, thus exposing the host bacterium to non-specific lysis by the bdellovibrio exoenzyme (second stage). The enhancement of lysis of living Pseudomonas fuorescens by multiple attachment of washed Bdellovibrio bacteriovorus A3.12 organisms after addition of exoenzyme- 
containing culture supernatant fluid further supports the two-stage interpretation of lysis. The morphology of lysis by exoenzyme-producing bdellovibrio strains (P1. 1, figs. 3-5) is markedly different from the sequence observed with strain 321 (Pl. 2, figs. 1-4), or strain 109 ( $\mathrm{Pl} .2$, fig. 5), which did not form exoenzyme or only formed trace amounts. In these latter strains, the absence of exoenzyme production would then allow the formation of spheroplasts or cytoplasmic extrusions.

Sensitization of various Gram-negative bacteria to the action of proteolytic enzymes by dissociation of the outer lipoprotein layer of the cell wall has been demonstrated by many investigators who have used : heat treatment (Salton, 1958; Horikoshi \& Shigeji, 1959; Becker \& Hartsell, 1954; Bender, 1963); freezing and thawing (Kohn, 1960); extraction with lipid solvent or alkali (Bender, 1963; Becker \& Hartsell, 1955) or with EDTA (Repaske, 1958). Treatment of host bacteria by heat, $5 \%(v / v)$ butanol, EDTA or acid in our experiments sensitized bacteria to the lytic activity of strain A3.12 exoenzyme.

In contrast to the work of Fukasawa \& Nikaido (1960) on the loss of receptor site for phage P 22 in Salmonella typhimurium, Bdellovibrio bacteriovorus 109 did not lose its ability to attach to and to lyse hosts such as UDP-galactose-4-epimeraseless Escherichia coli mutants in the absence of galactose, and the UDPG synthetase defective mutant of $\boldsymbol{E}$. coli. The polysaccharide composition of the cell walls of these host mutants does not seem, therefore, to be of critical importance for the attachment of the parasites.

We are grateful to Professor R. Y. Stanier for his hospitality in making it possible for one of us (M.S.) to spend a sabbatical leave in his laboratory, for suggestion of the subject and for his continued interest in this work. We thank Dr H. Stolp for kindly making his bdellovibrio strains available to us.

\section{REFERENCES}

Becker, M. E. \& Hartsell, S. E. (1954). Factors affecting bacteriolysis using lysozyme in dual enzyme systems. Arch. Biochem. Biophys. 53, 402.

Becker, M. E. \& Hartsell, S. E. (1955). The synergistic action of lysozyme and trypsin in bacteriolysis. Arch. Biochem. Biophys. 55, 257.

Bender, H. (1963). Untersuchungen an Myxococcus xanthus. Partielle Lyse von Pullularia pullulans und einigen echten Hefen durch ein extracelluläres Enzymsystem. Arch. Mikrobiol. 45, 405.

Cohen-Bazire, G., Sistrom, W. R. \& Stanier, R. Y. (1957). Kinetic studies of pigment synthesis by non-sulfur bacteria. J. Cell. comp. Physiol. 49, 25.

Fukasawa, T., Jokura, K. \& Kurahaser, K. (1962). A new enzyme defect of galactose metabolism in Escherichia coli K-12 mutants. Biochem. biophys. Res. Comm. 7, 121.

Fukasawa, T. \& Nikaido, H. (1960). Formation of phage receptors induced by galactose in a galactose-sensitive mutant of Salmonella. Virology, 11, 508.

Horikoshi, K. \& ShIGesI, I. (1959). Effect of lytic enzyme from Bacillus circulans and chitanase from Streptomyces sp. on Aspergillus oryzae. Nature, Lond. 183, 186.

КонN, A. (1960). Lysis of frozen and thawed cells of Escherichia coli by lysozyme, and their conversion into spheroplasts. J. Bact. 79, 697.

McCrady, M. H. (1918). Table for rapid interpretation of fermentation-tube results. Publ. Hlth J. 9, 169.

MAGER, J. (1964). A factor required for growth initiation of Pasteurella tularensis. Nature, Lond. 203, 898. 
Noller, E. C. \& HARTsell, S. E. (1961 a). Bacteriolysis of Enterobacteriaceae. Lysis of four lytic systems utilizing lysozyme. J. Bact. 81, 482.

Noller, E. C. \& Hartsell, S. E. (1961 b). Bacteriolysis of Enterobacteriaceae. Pre- and co-lytic treatments potentiating the action of lysozyme. J. Bact. 81, 492.

REPASKE, R. (1958). Lysis of Gram-negative organisms and the role of versene. Biochim. biophys. Acta, 30, 225.

Salton, M. R. J. (1958). The lysis of microorganisms by lysozyme and related enzymes. J. gen. Microbiol. 18, 481.

Stolp, H. \& Petzold, H. (1962). Untersuchungen über einen obligat parasitischen Mikroorganismus mit lytischer Aktivität fur Pseudomonas Bakterien. Phytopathol. Z. 45, 364.

Stolp, H. \& StarR, M. (1963). Bdellovibrio bacteriovorus gen. et sp.n., a predatory, ectoparasitic and bacteriolytic microorganism. Antonie van Leeurvenhoek, 29, 217.

SundaraJan, T. A., Rapin, A. M. C., \& Kalckar, H. M. (1962). Biochemical observations on $E$. coli mutants defective in uridine diphosphoglucose. Proc. natn. Acad. Sci. U.S.A. 48, 2187.

Yarmolinsky, M. B., Wiesmeyer, H., Kalckar, H. M. \& Jordan, E. (1959). Hereditary defects in galactose metabolism in Escherichia coli mutants, II. Galactose-induced sensitivity. Proc. natn. Acad. Sci. U.S.A. 45, 1786.

\section{EXPLANATION OF PLATES}

All figures (except Figs. 6-8; PI. 1) photographed under oil immersion in Reichert Zetopan Phase Contrast microscope, $\times 1200$.

\section{PLATE 1}

Fig. 1. Degenerate form of a host-independent bdellovibrio isolate, 3 to 5 -day-old culture in medium NB.

Fig. 2. Attachment of host-independent Bdellovibrio bacteriovorus A 3.12 isolate on Pseudomonas fluorescens $\mathbf{2}$ min. after mixing with host cells. The 48 -hr-old parasite culture was grown in NB medium.

Figs. 3-5. Morphological changes in host organisms (see explanation Fig. 2 above) 30-60 min. after mixing cultures.

Figs. 6-8. Different plaque types of host-independent strain A3.12 isolates after 4 days incubation $\left(30^{\circ}, \mathrm{NB} / 10\right.$ medium as described in Methods) on Pseudomonas fluorescens lawns.

\section{PLATE 2}

Figs. 1-4. Formation of cytoplasmic extrusions of Pseudomonas phaseolicola induced by Bdellovibrio bacteriovorus 321 photographed 30-60 min. after mixing host organisms with parasites from two-membered culture in which hosts had been fully lysed.

Fig. 5. Spheroplast formation of Pseudomonas fluorescens induced by strain 109 photographed 30-60 min. after mixing host organisms with parasites from two-membered culture in which hosts had been fully lysed. 

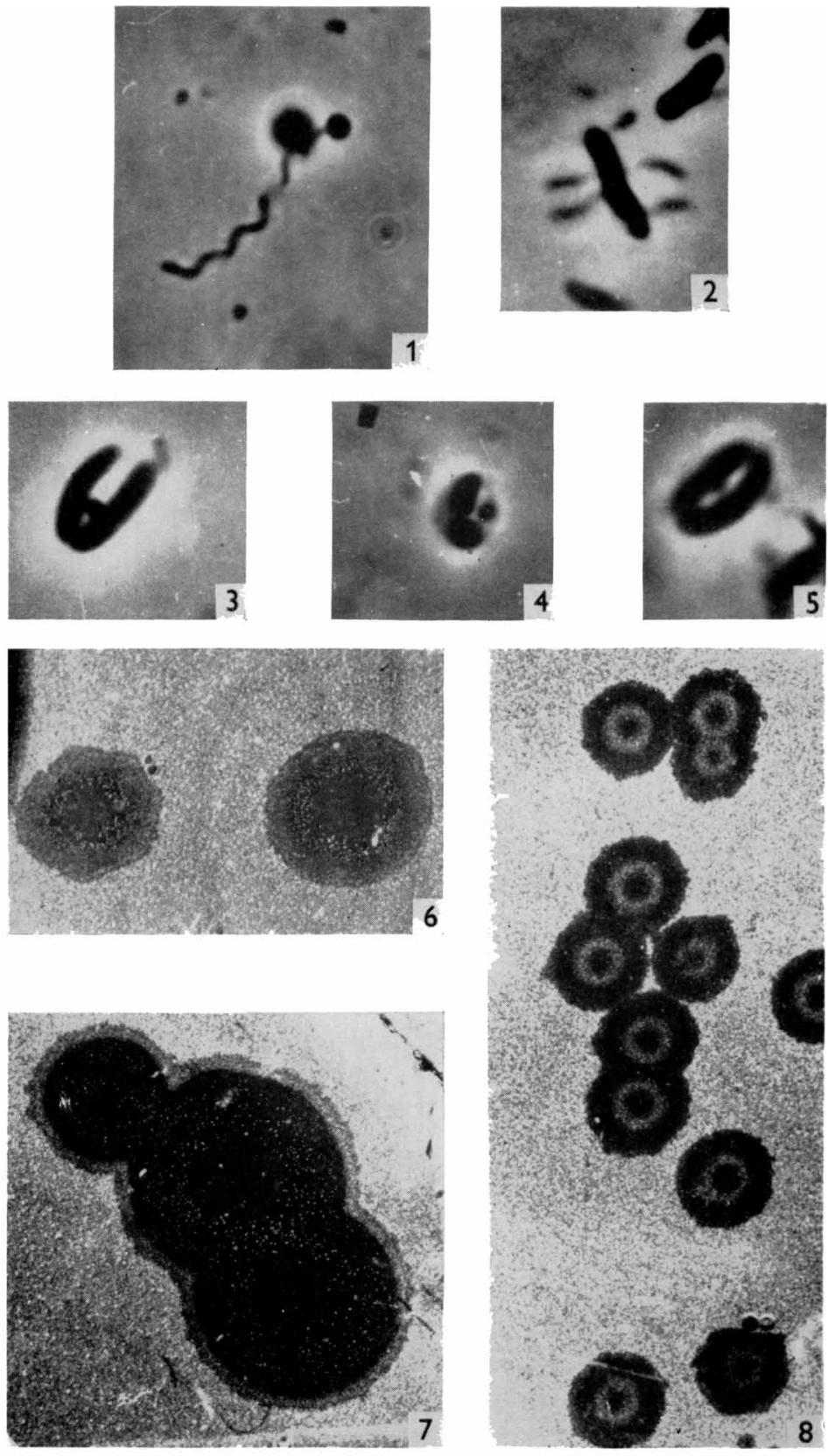

$1 \mathrm{~cm}$. 

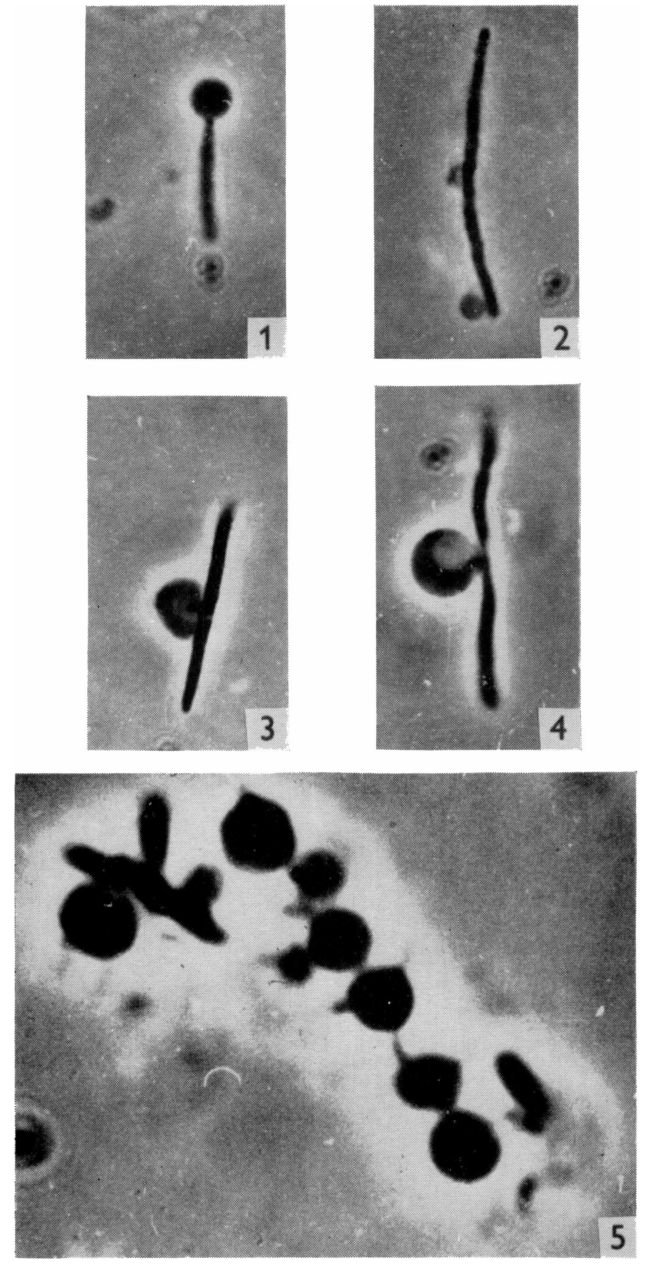

M. SHILO ANI B. BRUFT 